\title{
Reliability Assessment of Wind Turbines
}

\author{
John Dalsgaard Sørensen \\ Dept. of Civil Engineering, Aalborg University, Aalborg, Denmark \& DTU Wind Energy, Risø \\ Campus, Denmark
}

\begin{abstract}
Wind turbines can be considered as structures that are in between civil engineering structures and machines since they consist of structural components and many electrical and machine components together with a control system. Further, a wind turbine is not a one-of-a-kind structure but manufactured in series production based on many component tests, some prototype tests and zeroseries wind turbines. These characteristics influence the reliability assessment where focus in this paper is on the structural components. Levelized Cost Of Energy is very important for wind energy, especially when comparing to other energy sources. Therefore much focus is on cost reductions and improved reliability both for offshore and onshore wind turbines. The wind turbine components should be designed to have sufficient reliability level with respect to both extreme and fatigue loads but also not be too costly (and safe). In probabilistic design the single components are designed to a level of reliability, which accounts for an optimal balance between failure consequences, cost of operation \& maintenance, material costs and the probability of failure. Furthermore, using a probabilistic design basis for reliability assessment it is possible to design wind turbines such that site-specific information on climate parameters can be included. Illustrative examples are presented considering uncertainty modeling, reliability assessment and reliability-based calibration of partial safety factors for structural wind turbine components exposed to extreme loads and fatigue loads.
\end{abstract}

\section{INTRODUCTION}

The structural response of wind turbines is highly dependent on the wind turbulence, aerodynamics, dynamics of the structural system and the control system applied. Wind turbines consist of a number of different components including structural components and many electrical and machine components together with a control system. Further, a wind turbine is not a one-of-a-kind structure but manufactured in series production based on many component tests and some prototype tests and zero-series wind turbines allowing updating of knowledge though the design process. These characteristics influence the reliability assessment where focus in this paper is on the structural components. However, reliability modelling of faults of the electrical, machine and control components is also described in this paper since they also influence the reliability assessment of the structural components.

Levelized Cost Of Energy (LCOE) is very important for wind energy, especially when comparing to other energy sources. Therefore focus is on cost reductions and improved reliability both for offshore and onshore wind turbines. The turbine components should be designed to have sufficient reliability with respect to both extreme and fatigue loads but they should not be too safe (and costly). This paper presents models for uncertainty modeling and reliability assessment of especially the structural components such as tower, blades, substructure and foundation considering both extreme and fatigue loads.

In traditional deterministic design based on design standards, the structural costs are among other things determined by the value of the partial safety factors, which reflects the 
uncertainty related to the design parameters and the reliability level required. Improved design with a consistent reliability level for all components can be obtained by use of probabilistic design methods with explicit consideration of uncertainties connected to loads, strengths and numerical models / calculation methods. In probabilistic design the single components are designed to a level of reliability, which accounts for an optimal balance between failure consequences, cost of operation \& maintenance, material costs and the probability of failure. Furthermore, using a probabilistic design basis it is possible to design wind turbines such that site-specific information on climate parameters applied.

Design of wind turbines is basically done based on the IEC 61400 series of standards, where IEC 61400-1 (2005) is the basic standard specifying the requirements to structural reliability. This standard is being revised and this paper describes reliability analyses performed as basis for revising the partial safety factors in CD 61400-1 ed. 4 (2014). The general reliability models in this paper are partly based on the models in Sørensen (2013).

As mentioned above the reliability of the electrical and mechanical components are very important. The following references describe statistics and methods for reliability assessment of these components, see e.g. Tavner et al. (2007), Spinato (2008), Tavner (2012), Tavner et al. (2013) and Faulstich et al. (2011).

General descriptions on reliability assessment of wind turbines concentrating mostly on the structural components and application of structural reliability methods can be found in e.g. Veldkamp (2006), Toft (2010), Agarwal (2008) and Sørensen \& Toft (2010).

For Offshore wind turbines especially the support structures and the foundation contribute significantly to the levelized cost of energy and therefore reliability assessment of these components are important, see e.g. Dong (2012), Andersen et al. (2012) and Vahdatirad et al. (2011).
Illustrative examples are presented considering uncertainty modeling, reliability assessment and reliability-based calibration of partial safety factors for structural wind turbine components exposed to extreme loads and fatigue loads, respectively.

\section{RELIABILITY MODELLING}

Wind turbines are generally designed for the following main Design Load Cases (DLC), see IEC 61400-1 (2005):

- DLC 1: Failure during normal operation in extreme load or by fatigue

- DLC 2: Failure under fault conditions (e.g. failure of electrical / mechanical components or loss of grid connection) due to extreme loads or by fatigue

- DLC 3, 4 and 5: Failure during start up, normal shut down or emergency shut down

- DLC 6: Failure when the wind turbine is idling / parked and does not produce electricity. Failure can be by extreme loads or by fatigue

- DLC 7: Failure during transportation and installation

- DLC 8: Failure during transport, assembly, maintenance and repair

For reliability modeling a wind turbine can be modeled as a system of components. The model can be extended to include more wind turbines in a larger system, e.g., a wind farm. The components can generally be divided in two groups:

Electrical and mechanical components where the reliability typically is modeled using classical reliability models, i.e. the main descriptor is the failure rate, $\lambda$ or the Mean Time between Failure, MTBF $=1 / \lambda$. Further, the bath-tub model is often used to describe the time dependent behavior of the failure rate or the hazard rate. The reliability is typically modeled by a Weibull distribution. Using e.g. FMEA (Failure Mode and Effect Analysis) or FTA (Failure Tree Analysis), system models can be 
established and the systems reliability can be estimated, see e.g. Tavner et al. (2007).

Structural elements such as tower, main frame, blades and the support structure / foundation with failure modes that can be described by limit state equations. Failure of the tower can e.g. be buckling or fatigue. Failure of a blade could e.g. be buckling or and delamination of laminates. The parameters in the limit state equation $g(\mathbf{X})$ are assumed to be modeled by $n$ stochastic variables $\mathbf{X}=\left(X_{1}, \ldots, X_{n}\right)$. The probability of failure, $P_{f}$ can be estimated using Structural Reliability Methods, e.g. FORM / SORM / simulation methods, see e.g. Madsen et al. (1986), Ronold et al. (1999) and JCSS (2002).

An important part of a wind turbine is the control system which controls the energy output and limits the load effects in the structural wind turbine components. Failure of the control system can be very critical for both the electrical/mechanical and the structural components since the loads on these can increase dramatically. Therefore the reliability of the control system should be included in a reliability assessment of the whole wind turbine system.

In many instances fault of e.g. an electrical component might indirectly cause the increase of the fatigue damage level of the structural components or cause large extreme load effects. For example the probability of failure per year for a structural component considering e.g. for grid loss can be obtained from:

$$
P_{f, i}=P\left(F_{i} \mid \text { grid loss }\right) P_{\text {annual }}(\text { grid loss })
$$

where $P\left(F_{i} \mid\right.$ grid loss $)$ is the probability of failure of structural component $i$ given loss of grid and $P_{\text {annual }}($ grid loss) is the probability per year of loss of grid connection. Alternatively, the grid loss annual failure rate can be estimated directly based on the observed data; this estimate is denoted the mean annual failure rate of grid loss, $\lambda_{\text {grid loss }}$.

Next, the load case is considered where the wind turbine is parked, loss of the grid occurs and structural failure by an ultimate limit state
(DLC 6.2). The annual failure rate for this DLC can be estimated from:

$$
\lambda_{F_{1}}=\left\{\sum_{j} P\left(F_{i, j} \mid \text { extreme wind } \cap \text { grid loss }\right) \cdot P_{j}\right\} \cdot v_{\text {grid loss }}
$$

where $P\left(F_{i, j} \mid\right.$ extreme wind $\cap$ grid loss $)$ is the probability of failure for a specific failure mode, $j$ with extreme wind speed and 'misalignment position' $i$ at grid loss. $P_{i}$ is the probability of at 'misalignment position' $i$ at grid loss. $P\left(F_{i, j} \mid\right.$ extreme wind $\cap$ grid loss $)$ can be estimated by structural reliability methods for a specific failure mode modeling the mean wind speed as the annual extreme wind speed.

The above models can easily be extended to other fault types and to fatigue failure and can be used for direct assessment of the reliability of structural components of wind turbines, for planning of operation and maintenance and for calibrating the design rules in standards.

\section{TARGET RELIABILITY LEVEL}

For wind turbines the risk of loss of human lives in case of failure of a structural element is generally very small. Further, it can be assumed that wind turbines are systematically reconstructed in case of collapse or end of lifetime. In that case also target reliabilities based on annual probabilities should be used, see JCSS (2002).

It is assumed that for wind turbines a systematic reconstruction policy is used (a new wind turbine is erected in case of failure or expiry of lifetime); consequences of a failure are only economic (no fatalities and no pollution); cost of energy is very important which implies that the relative cost of safety measures can be considered large (material cost savings are important); and wind turbines are designed to a certain wind turbine class, i.e. not all wind turbines are 'designed to the limit'. 
Based on these considerations an appropriate target reliability level corresponding to a minimum annual probability of failure is considered be $5 \cdot 10^{-4}$ (annual reliability index equal to 3.3 ).

\section{RELIABILITY BASED CALIBRATION OF MATERIAL PARTIAL FACTORS}

This section describes an example where the following generic limit state equation for extreme load effects (ultimate limit states) in operation or standstill / parked is considered, see also Tarp-Johansen et al. (2002, 2003) and Sørensen \& Toft $(2010,2014)$ for more details:

$$
g=z b \delta R(\mathbf{X}, a)-X_{d y n} X_{\text {exp }} X_{\text {aero }} X_{\text {str }} L
$$

where $z$ is a design parameter, e.g. crosssectional area, $R()$ is the model for the load bearing capacity / resistance, $\delta$ is the model uncertainty for resistance assumed to have a mean value equal to 1 and coefficient of variation $V_{\delta}, b$ models the bias in the resistance model, $R(), \mathbf{X}$ is the vector of random variables (e.g. strength and stiffness parameters), $a$ is set of deterministic variables, e.g. geometrical parameters, $X_{d y n}$ models uncertainty related to modeling of the dynamic response, including uncertainty in damping ratios and eigenfrequencies, $X_{\text {exp }}$ models uncertainty related to the modeling of the exposure (site assessment) - such as the terrain roughness and the landscape topography, $X_{\text {aero }}$ models uncertainty in assessment of lift and drag coefficients and additionally utilization of BEM, dynamic stall models, etc., $X_{\text {str }}$ models uncertainty related to the computation of the load-effects given external load and $L$ models uncertainty related to the extreme load-effect due to wind loads. For simplicity no permanent loads are introduced, but could easily be included.

The stochastic model in Table 1 is used as 'representative', based partly on Tarp-Johansen et al. $(2002,2003)$.
Table 1: Stochastic models for physical, model and statistical uncertainties. LN: Lognormal; G: Gumbel; W: Weibull.

\begin{tabular}{|l|l|l|l|l|l|}
\hline $\begin{array}{l}\text { Vari } \\
\text {-able }\end{array}$ & $\begin{array}{l}\text { Dist } \\
\cdot\end{array}$ & $\begin{array}{l}\text { Me } \\
\text { an }\end{array}$ & COV & Quantile & Comment \\
\hline$R$ & LN & - & $\mathrm{V}_{R}$ & $5 \%$ & Strength \\
\hline$\delta$ & LN & - & $V_{\delta}$ & Mean & $\begin{array}{l}\text { Model } \\
\text { uncertainty }\end{array}$ \\
\hline $\begin{array}{l}L- \\
\text { DLC } \\
1.1\end{array}$ & $\mathrm{~W}$ & - & 0.15 & 0.98 & $\begin{array}{l}\text { Annual max } \\
\text { load effect } \\
\text { obtained by } \\
\text { load } \\
\text { extrapolation }\end{array}$ \\
\hline $\begin{array}{l}L \\
\text { DLC } \\
6.1\end{array}$ & G & - & 0.2 & 0.98 & $\begin{array}{l}\text { Annual } \\
\text { maximum } \\
\text { wind pressure }\end{array}$ \\
\hline$X_{\text {dyn }}$ & LN & 1 & 0.05 & Mean & \\
\hline$X_{\text {exp }}$ & LN & 1 & 0.15 & Mean & \\
\hline$X_{\text {aero }}$ & G & 1 & 0.10 & Mean & \\
\hline$X_{\text {str }}$ & LN & 1 & 0.03 & Mean & \\
\hline
\end{tabular}

The design equation for deterministic design corresponding to (3) is written

$$
\frac{z b R_{k}}{\gamma_{R}}-\gamma_{f} L_{k} \geq 0
$$

where $R_{k}$ is the characteristic value of load bearing capacity, $L_{k}$ is the characteristic value of variable load, $\gamma_{R}$ is a partial factor for resistance and $\gamma_{f}$ is a partial factor for load effect $=1.35$.

Table 2 and 3 show for DLC 1.1 and 6.1 the partial factor for the resistance, $\gamma_{R}$ calibrated to the above target annual failure probability equal to $510^{-4}$ assuming no bias, for various values of the coefficient of variation for strength, $\mathrm{V}_{R}$ and model uncertainty, $V_{\delta}$, see Sørensen \& Toft (2014) for details.

Table 2: Partial factors for resistance. DLC 1.1.

\begin{tabular}{|r|l|l|l|l|l|}
\hline$V_{\delta}=$ & 0,00 & 0,05 & 0,10 & 0,15 & 0,20 \\
\hline $\mathrm{V}_{R}=0,05$ & 1.16 & 1.18 & 1.24 & 1.35 & 1.49 \\
\hline 0,10 & 1.12 & 1.14 & 1.20 & 1.29 & 1.43 \\
\hline 0,15 & 1.11 & 1.13 & 1.19 & 1.28 & 1.40 \\
\hline 0,20 & 1.13 & 1.15 & 1.20 & 1.28 & 1.40 \\
\hline 0,25 & 1.17 & 1.18 & 1.23 & 1.31 & 1.42 \\
\hline
\end{tabular}


Table 3: Partial factors for resistance. DLC 6.1.

\begin{tabular}{|r|l|l|l|l|l|}
\hline$V_{\delta}=$ & 0,00 & 0,05 & 0,10 & 0,15 & 0,20 \\
\hline $\mathrm{V}_{R}=0,05$ & 1.14 & 1.16 & 1.20 & 1.28 & 1.40 \\
\hline 0,10 & 1.09 & 1.11 & 1.15 & 1.22 & 1.33 \\
\hline 0,15 & 1.07 & 1.08 & 1.12 & 1.19 & 1.29 \\
\hline 0,20 & 1.06 & 1.08 & 1.11 & 1.18 & 1.27 \\
\hline 0,25 & 1.07 & 1.09 & 1.12 & 1.19 & 1.28 \\
\hline
\end{tabular}

It is seen that the required partial factor, $\gamma_{R}$ increases with the uncertainty of the model, $V_{\delta}$ and is almost constant as function of the uncertainty of the strength, $\mathrm{V}_{R}$. The reason is that the characteristic value (5\% quantiles) for $R$ decreases more for increasing COV than the resulting design value of the load bearing capacity (obtained by the reliability analyses) decreases. Further, it is seen that the partial safety factors in Table 2 are conservative compared to Table 3. In CD 61400-1 ed. 4 (2014) $\gamma_{R}$ is assumed independent of $V_{R}$ and increasing linearly from 1.1 for $V_{\delta}=0 \%$ to 1.4 for $V_{\delta}=20 \%$.

To illustrate the importance of the uncertainty level of the load in extreme design load cases, a reduction factor that can be multiplied to the load partial safety factor, $\gamma_{f}$, is determined using the same assumptions as described above. It is assumed that the coefficient of variation of the material strength is $\mathrm{V}_{R}=0.10$ and the stochastic model in Table 1 is used as base case. The results are shown in Table 4.

Table 4: Reduction factor on load partial safety factor, $\gamma_{f}$.

\begin{tabular}{|l|l|l|l|l|l|}
\hline \multicolumn{1}{|c|}{$V_{\delta}=$} & 0.00 & 0.05 & 0.10 & 0.15 & 0.20 \\
\hline $\operatorname{COV}(L)=0.20$ & 0.98 & 0.97 & 0.98 & 0.98 & 0.97 \\
\hline $\operatorname{COV}\left(X_{\text {dyn }}\right)=0.03$ & 0.99 & 0.99 & 0.99 & 0.99 & 0.99 \\
\hline $\operatorname{COV}\left(X_{\text {exp }}\right)=0.10$ & 0.93 & 0.93 & 0.93 & 0.94 & 0.94 \\
\hline $\operatorname{COV}\left(X_{\text {aero }}\right)=0.05$ & 0.93 & 0.93 & 0.93 & 0.94 & 0.94 \\
\hline $\operatorname{COV}\left(X_{\text {str }}\right)=0.00$ & 0.99 & 0.99 & 0.99 & 1.00 & 0.99 \\
\hline
\end{tabular}

From Table 4 it is seen that decreasing the uncertainty on the load effect, $L$ results in a slightly reduced $\gamma_{f}$. This change is mainly because the characteristic value also changes when the COV changes. Further, decreasing the $\mathrm{COV}$ on $X_{d y n}$ (dynamic response) from 0.05 to 0.03 results in a very small reduction of $\gamma_{f}$. next, decreasing the COV on $X_{\text {exp }}$ (site assessment) from 0.15 to 0.10 and $X_{\text {aero }}$ (aerodynamics) from 0.10 to 0.05 results in a reduction of $\gamma_{f}$ of the order $6-7 \%$. Finally, decreasing the COV on $X_{\text {str }}$ (structural analysis) from 0.03 to 0.00 results in almost no reduction of $\gamma_{f}$.

This clearly illustrates the importance of careful assessment of the wind load parameters for the partial safety factors and thus the resulting design. Especially the uncertainty related to site assessment and aerodynamic parameters are seen to be very important.

Finally, it is noted that the partial safety factors obtained as described above and implemented in the draft CD IEC 61400-1 ed. 4 (2014) generally only result in slight changes in the design values compared to the values obtained by the IEC $61400-1$ ed. 3 (2005) standard. The main advantage of the new research and development performed as basis for the derivation of the partial safety factors is that a reliability-based approach has been used which opens up for application of probabilistic design of large wind turbines. One of the advantages is also that if more information and e.g. less uncertainty of some parameters are documented, then this information can be applied to obtain more cost-effective wind turbine components.

\section{RELIABILITY BASED CALIBRATION OF SAFETY FACTORS FOR FATIGUE}

For wind turbine steel substructures fatigue can be a critical failure mode for welded details, especially if joints with high stress.

Linear or bi-linear SN-curves are assumed to be used to model the fatigue life with the linear $\mathrm{SN}$ relation written as

$$
N=K(\Delta \sigma)^{-m}
$$


where $N$ is the number of stress cycles to failure with constant stress ranges $\Delta \sigma . K$ and $m$ are dependent on the fatigue critical detail. The fatigue strength $\Delta \sigma_{F}$ is defined as the value of $S$ for $N_{D}=2 \cdot 10^{6}$.

The probability of failure in year $t$ given survival up to year $t$ is estimated using a limit state equation based on SN-curves, Miner's rule for linear accumulation of fatigue damage and by introducing stochastic variables accounting for uncertainties in fatigue loading and strength. The stochastic model shown in Table 5 is considered as representative for a fatigue sensitive welded steel detail where the fatigue strength is represented by a bi-linear SN-curve. It is assumed that the design lifetime is $T_{L}=25$ year.

Table 5: Stochastic model.

\begin{tabular}{|c|c|c|c|c|}
\hline $\begin{array}{c}\text { Vari } \\
\text {-able }\end{array}$ & $\begin{array}{l}\text { Distrib } \\
\text { ution }\end{array}$ & $\begin{array}{l}\text { Expec } \\
\text { ted } \\
\text { value }\end{array}$ & $\begin{array}{l}\text { Std. } \\
\text { dev. } \\
\text { COV }\end{array}$ & Comment \\
\hline$\Delta$ & $\mathrm{N}$ & 1 & $\begin{array}{c}C O V_{\Delta} \\
=0.30\end{array}$ & $\begin{array}{l}\text { Model } \\
\text { uncertainty } \\
\text { Miner's rule }\end{array}$ \\
\hline$X_{\text {Wind }}$ & LN & 1 & $C O V_{\text {Wind }}$ & $\begin{array}{l}\text { Model } \\
\text { uncertainty } \\
\text { wind load }\end{array}$ \\
\hline$X_{S C F}$ & LN & 1 & $C O V_{S C F}$ & $\begin{array}{l}\text { Model } \\
\text { uncertainty } \\
\text { stress } \\
\text { concentration } \\
\text { factor }\end{array}$ \\
\hline$m_{1}$ & $\mathrm{D}$ & 3 & & $\begin{array}{l}\text { Slope } \\
\text { surve }\end{array}$ \\
\hline $\log K$ & $\mathrm{~N}$ & $\begin{array}{l}\text { from } \\
\Delta \sigma_{D}\end{array}$ & $\begin{array}{l}\sigma_{\log K_{1}}= \\
0.2\end{array}$ & $\begin{array}{l}\text { Parameter } \\
\text { SN curve }\end{array}$ \\
\hline$m_{2}$ & $\mathrm{D}$ & 5 & & $\begin{array}{ll}\begin{array}{l}\text { Slope } \\
\text { curve }\end{array} & \text { SN }\end{array}$ \\
\hline $\log K$ & $\mathrm{~N}$ & $\begin{array}{l}\text { from } \\
\Delta \sigma_{D}\end{array}$ & $\begin{aligned} & \sigma_{\log K_{2}} \\
= & 0.2\end{aligned}$ & $\begin{array}{l}\text { Parameter } \\
\text { SN curve }\end{array}$ \\
\hline$\Delta \sigma_{F}$ & $\mathrm{D}$ & $\begin{array}{l}71 \\
\mathrm{MPa}\end{array}$ & & $\begin{array}{l}\text { Fatigue } \\
\text { strength }\end{array}$ \\
\hline
\end{tabular}

Table 6: Required partial factors $\gamma_{f} \gamma_{m}$ as function of COV for fatigue load.

\begin{tabular}{|c|c|c|c|c|c|c|c|}
\hline COV $_{\text {load }}$ & 0,00 & 0,05 & 0,10 & 0,15 & 0,20 & 0,25 & 0,30 \\
\hline & 1.04 & 1.06 & 1.12 & 1.21 & 1.32 & 1.43 & 1.56 \\
\hline
\end{tabular}

Assuming that a coefficient of variation for the fatigue load ranges is typically within the interval $15-20 \%$ the partial factor $\gamma_{m}=1.25$ and $\gamma_{f}$ in Table 7 are given in CD 61400-1 ed. 4 (2014).

Table 7: Recommended partial safety factor for fatigue stress ranges, $\gamma_{f}$.

\begin{tabular}{|l|l|l|l|l|l|l|}
\hline COV $_{\text {load }}$ & $0-$ & $0.05-$ & $0.10-$ & $0.15-$ & $0.20-$ & $0.25-$ \\
& 0.05 & 0.10 & 0.15 & 0.20 & 0.25 & 0.30 \\
\hline$\gamma_{f}$ & 0.85 & 0.90 & 0.95 & 1.00 & 1.10 & 1.20 \\
\hline
\end{tabular}

Information about assessment of $\mathrm{COV}_{\text {Wind }}$ and $C O V_{S C F}$ can be found in de las Heras et al. (2013), Sørensen (2012) and Sørensen \& Toft (2014). Table 8 shows examples of how to model the uncertainty related to $X_{\text {wind }}$, see Sørensen \& 
Toft (2014). The contribution of the different sources of uncertainties to the total $X_{\text {wind }}$ could be evaluated with sensitivity analysis.

Table 8: Examples of the total coefficient of variation for fatigue load $\mathrm{COV}_{\text {Wind }}$.

$C O V_{\text {Wind }}=0.10-0.15$
Site assessment:

Site assessment:

- $\quad$ More than 2 years of climatic data, corrected with MCP techniques.

- Wind measurements above and below wind turbine hub height.

- $\quad$ Flat terrain with low roughness

Dynamic response:

- Structural dynamic effects through modal analysis, with at least 4 modes considered for blade and tower.

- Mass and stiffness properties defined with FEM and validated with real scale specimens.

- $\quad$ Eigenvalues and damping validated with real scale tests.

Aerodynamic coefficients:

- $\quad$ Airfoil data experimentally validated in wind tunnel at different Re numbers

- Airfoil data including 3D effects

- Attached flow in all operating regimes

- $\quad$ BEM, including Dynamic stall and Tip and hub loss included

- Dynamic wake inflow model

- Quality control of shape of manufactured blades

$C O V_{\text {Wind }}=0.15-0.20$

Site assessment:

- Minimum 1 year of climatic data.

- Wind measurements at hub height and below.

- Non-complex site with medium roughness.

Dynamic response:

- Structural dynamic effects through modal analysis, with 2 modes considered for blade and tower.

- Mass and stiffness properties defined with FEM but not validated with real scale specimens.

- $\quad$ Eigenvalues and damping not validated with real scale tests.

Aerodynamic coefficients:

- Airfoil data based on CFD, but not measured in wind tunnel.
- 3D effects not included in airfoil data

- Attached flow in all operating regimes

- BEM, but not including dynamic stall effects nor tip and hub losses

- $\quad$ Static wake inflow model $C O V_{\text {Wind }}=0.20-0.25$

Site assessment:

- Less than 1 year of data, not corrected with MCP techniques Wind measurements below hub height.

- Complex terrain.

Dynamic response:

- $\quad$ Structural dynamic effects not considered Aerodynamic coefficients:

- Airfoil data based on similar airfoils or for a single Re number.

- 3D effects not included in airfoil data

- $\quad$ Stall flow in relevant operating regimes

- $\quad$ BEM, but not including dynamic stall effects nor tip and hub losses

- No model for wake effects

- Dirt and erosion on blades

\section{SUMMARY}

This paper describes basic aspects for reliability analysis of wind turbines with special focus on structural components. Based on the main design load cases to be considered in design of wind turbine components the corresponding reliability modeling is presented including the effects of the control system and possible faults due to failure of electrical / mechanical components and e.g. loss of grid connection. Further, the target reliability level for wind turbine structural components is discussed together with uncertainty modeling of the main uncertainties related to structural wind turbine components.

Two examples are presented with uncertainty modeling and reliability-based calibration of partial safety factors for structural components exposed to extreme loads and fatigue, respectively. 


\section{ACKNOWLEDGEMENTS}

This work has been partly funded by the Norwegian Centre for Offshore Wind Energy (NORCOWE) under grant 193821/S60 from the Research Council of Norway (RCN). NORCOWE is a consortium with partners from industry and science, hosted by the Christian Michelsen Research Institute, and partly by Danish Energy Technology Development and Demonstration (EUDP) project titled, "Demonstration of a basis for tall wind turbine design", Project no 64011-0352.

\section{REFERENCES}

Agarwal, P. (2008) Structural Reliability of Offshore Wind Turbines. PhD thesis, University of Texas at Austin.

Andersen, L.V., M.J. Vahdatirad, M.T. Sichani \& J.D. Sørensen (2012) Natural frequencies of wind turbines on monopile foundations in clayey soils-A probabilistic approach. Computers and Geotechnics, Vol. 43, pp 1-11.

de las Heras, E.G., R. Gutiérrez, E. Azagra \& J.D. Sørensen (2013) Assessment of wind turbine for site-specific conditions using probabilistic methods. Proc. EWEA 2013.

Dong, W. (2012) Time-domain fatigue response and reliability analysis of offshore wind turbines with emphasis on welded tubular joints and gear components. PhD thesis, NTNU, Trondheim.

EN 1990 (2002) Basis of structural design. CEN.

Faulstich, S., P. Lyding \& B. Hahn (2011) Component reliability ranking with respect to WT concepts and external environmental conditions. UpWind report

IEC 61400-1 (2005) Wind turbine generator systems - Part 1: Safety requirements. $3^{\text {rd }}$ edition.

IEC 61400-1 (2014) Wind turbine generator systems - Part 1: Safety requirements. CD draft of $4^{\text {th }}$ edition.

JCSS (Joint Committee on Structural Safety) (2002) Probabilistic Model Code. http://www.jcss.byg.dtu.dk/

Madsen, H. O., S. Krenk \& N.C. Lind (1986) Methods of Structural Safety, Dover Publications, Inc.

Ronold, K.O., J. Wedel-Heinen \& C.J. Christensen 1999. Reliability-based fatigue design of windturbine rotor blades, Engineering Structures, Vol. 21, pp. 1101-1114.

Spinato, F. (2008) The Reliability of Wind Turbines. $\mathrm{PhD}$ thesis, Durham University, England.
Sørensen, J.D. \& and H.S. Toft (2010) Probabilistic design of wind turbines. Energies, Vol. 3, pp. 241257.

Sørensen, J.D. (2012) Reliability-based calibration of fatigue safety factors for offshore wind turbines. International Journal of Offshore and Polar Engineering. Vol. 22, No. 3, pp. 234-241.

Sørensen, J.D. (2013) Reliability assessment of wind turbines. Proc. ESREL2013, Amsterdam, 2013.

Sørensen, J.D. \& H.S. Toft (2014) Safety Factors IEC 61400-1 ed. 4 - background document. DTU Wind Energy-E-Report-0066 (EN).

Tarp-Johansen, N.J., P.H. Madsen \& S.T. Frandsen (2002) Partial safety factors for extreme load effects. RISØ-R-1319(EN).

Tarp-Johansen, N.J., P.H. Madsen \& S.T. Frandsen (2003) Calibration of Partial Safety Factors for Extreme Loads on Wind Turbines Proc CD-ROM - European wind energy conference and exhibition (EWEC), (EWEA, Brussels, 2003).

Tavner, P.J., J. Xiang \& F. Spinato (2007) Reliability analysis for wind turbines. Wind Energy, Vol. 10, pp. 1-18.

Tavner, P. (2012) Offshore Wind Turbines: Reliability, Availability and Maintenance. Institution of Engineering and Technology.

Tavner, P.J., D. M. Greenwood, M. W. G. Whittle, R. Gindele, S. Faulstich \& B. Hahn (2013) Study of weather and location effects on wind turbine failure rates. Wind Energy, Vol. 16, pp. 175-187.

Toft, H.S. (2010) Probabilistic Design of Wind Turbines. $\mathrm{PhD}$ thesis, Aalborg University.

Vahdatirad, M., L. Andersen \& J.D. Sørensen (2011) The Dynamic Stiffness of Surface Footings for Offshore Wind Turbines: reliability based assessment. Proc. Thirteenth International Conference on Civil, Structural and Environmental Engineering Computating. CivilComp Press (Civil-Comp Proceedings).

Veldkamp, D. (2006) Chances in Wind Energy - A Probabilistic Approach to Wind Turbine Fatigue Design. PhD thesis, DUWIND Delft University, Wind Energy Research Institute, Delft. 